\title{
Particle Size Distributions and Organic-Inorganic Compositions of Suspended Particulate Matters Around the Bohai Strait
}

\author{
WANG Xiao $^{1)}$, BIAN Changwei ${ }^{2), *}$, BI Rong ${ }^{3)}$, JIANG Wensheng ${ }^{1)}$, ZHANG Hua ${ }^{4)}$, \\ and ZHANG Xueqing ${ }^{1)}$
}

1) Key Laboratory of Marine Environment and Ecology, Ocean University of China, Qingdao 266100, P. R. China

2) Key Laboratory of Physical Oceanography, Ocean University of China, Qingdao 266003, P. R. China

3) Key Laboratory of Marine Chemistry Theory and Technology, Ocean University of China, Qingdao 266100, P. R. China

4) Yantai Institute of Coastal Zone Research, Chinese Academy of Science, Yantai 264003, P. R. China

(Received January 25, 2016; revised May 9, 2016; accepted September 15, 2016)

(c) Ocean University of China, Science Press and Springer-Verlag Berlin Heidelberg 2017

\begin{abstract}
Laser in situ scattering and transmissometry (LISST) significantly improves our ability to assess particle size distribution (PSD) in seawater, while wide-ranging measurements of the organic-inorganic compositions of suspended particulate matters (SPM) are still difficult by using traditional methods such as microscopy. In this study, PSD properties and SPM compositions around the Bohai Strait (China) were investigated based on the measurements by LISST in combination with hydro-biological parameters collected from a field survey in summer 2014. Four typical PSD shapes were found in the region, namely right-peak, left-peak, double-peak and negative-skew shapes. The double-peak and negative-skew shapes may interconvert into each other along with strong hydrodynamic variation. In the upper layer of the Bohai Sea, organic particles were in the majority, with inorganic particles rarely observed. In the bottom layer, SPM were the mixture of organic and inorganic matters. LISST provided valuable baseline information on size-resolved organic-inorganic compositions of SPM: the size of organic particles mainly ranged from 4 to $20 \mu \mathrm{m}$ and 40 to 100 $\mu \mathrm{m}$, while most SPM ranging from 20 to $40 \mu \mathrm{m}$ were composed of inorganic sediment.
\end{abstract}

Key words particle size distribution; phytoplankton; sediment; field survey; Bohai Sea

\section{Introduction}

Suspended particulate matters (SPM) consist of particulate organic matters (POM) and inorganic matters (PIM), and they play significant roles in marine ecosystems such as regulating sediment transport flux and biogeochemical cycling. Identification of particle size distribution (PSD) of SPM helps to understand the structure and functioning of aquatic ecosystems (Karageorgis et al., 2012), as well as the source and transport mechanisms of sediment in the ocean (Hu et al., 2009; Zeng et al., 2011). Moreover, determination of organic-inorganic compositions of SPM is crucial to accurately assess the contributions of phytoplankton functional groups to primary production and to estimate the terrigenous inorganic sediment transport flux into open seas (Conan et al., 2007; de Moraes et al., 2014; Hu et al., 2009).

Traditional microscopic methods, sieve methods and sedimentation methods have been used to estimate the PSD of SPM, and the microscopic methods are also the primary way to analyze SPM compositions (Brewin et al.,

\footnotetext{
* Corresponding author. Tel: 0086-532-66782269

E-mail: bianchangwei@ouc.edu.cn
}

2014; Nair et al., 2008; Reynolds et al., 2010). However, the labor-costing and time-consuming measurement processes of these traditional methods hinder the studies of PSD and SPM compositions (Groundwater et al., 2012). Thus, increasing efforts have been made to estimate the size structure of SPM at a high spatial and temporal resolution with remote-sensing methods (Li et al., 2013; Nair et al., 2008; Qing et al., 2014), while these methods only provide PSD information in the surface layer of seawater. Little is known about SPM compositions in the open seas, especially for their spatiotemporal variations.

Laser in situ scattering and transmissometry (LISST) has been widely used to measure PSD in marine sediments, phytoplankton community and other natural particle assemblages, providing high-frequency and continuous PSD results (Czuba et al., 2015; Fettweis et al., 2014; Markussen and Andersen, 2013; Renosh et al., 2014; Reynolds et al., 2010; Xi et al., 2015). LISST greatly improves our understanding of PSD in seawater, but the SPM composition remains unclear. In general, organic and inorganic particulate matters have specific particle sizes in particular seas. If there are distinct differences between organic and inorganic particle size, SPM can be divided into organic and inorganic parts based on the particle size information. Since LISST provides volumetric 
concentration information of SPM for specific particle size, it has untapped potential in SPM composition research. The Bohai Sea is a particularly good ecosystem to investigate the applicability of LISST in identifying SPM compositions as it is turbid and characterized by intense algae blooms (Jiang et al., 2004; Wei et al., 2004).

In the western Pacific, the marginal Bohai Sea is a shallow semi-closed sea with an average water depth of $18 \mathrm{~m}$, the deepest part (about $70 \mathrm{~m}$ ) being located in the Bohai Strait (Fig.1). The Yellow River (also called Huanghe River), as the second largest river in the world in terms of sediment load, discharges $1.1 \times 10^{9} \mathrm{t}$ sediment (19651974) into the Bohai Sea annually (Milliman and Meade, 1983). Due to the increasing water consumption, soil conservation and water regulation, the Yellow River sediment discharge (2000-2010) decreased to $0.14 \times 10^{9} \mathrm{t}$ (Dong et al., 2015; Yu et al., 2013). Approximately $70 \%-90 \%$ of the Yellow River discharged sediment was deposited at the mouth (Bornhold et al., 1986; Milliman and Meade, 1983), with 10\%-30\% being transported beyond the coastal area (Alexander et al., 1991; Bornhold et al., 1986; Meade, 1996; Yang and Liu, 2007), providing the primary inorganic source of SPM in the Bohai Sea. Phytoplankton is the primary components of the organic SPM in the Bohai Sea (Liu et al., 2014; Sun et al., 2003).

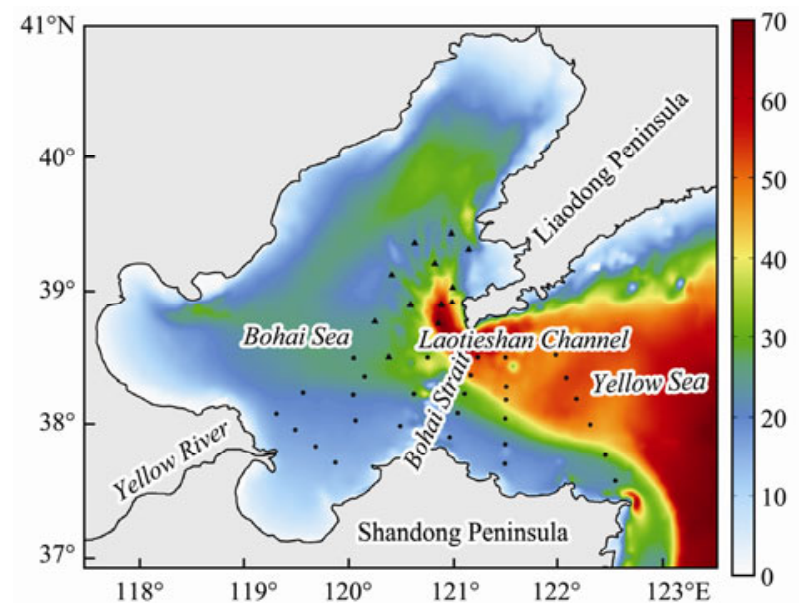

Fig.1 Bathymetry (m) of the Bohai Sea and location of sampling stations (black points and triangles) in summer 2014. The measurements marked with triangle were conducted after a strong wind event.

The Bohai Sea used to be one of the most important fishing grounds in China. In recent decades, the ecosystem in the Bohai Sea has been significantly impacted by anthropogenic activities such as reclamation, pollutants from rivers, and oil field exploitation (Gao et al., 2015; Pelling et al., 2013; Wang, 2015). Remediating and conserving the ecological functions of the Bohai Sea become a hot topic in hydrology, ecology, sedimentation and even in business fields, with billions of dollars spent to restore this ecosystem (Gao et al., 2014). Especially, the SPM in the Bohai Sea has attracted particular interest, because most of its organic components consist of phytoplankton and its inorganic components are capable of affecting the ambient environment of the planktons (Liu et al., 2013). Most previous studies of SPM in the Bohai Sea focus on phytoplankton biomass and suspended sediment concentrations (Liu et al., 2014; Qiao et al., 2010; Sun et al., 2008; Wang, 2015; Wang et al., 2014; Yang et al., 2011). However, few field studies of the PSD have been made, and little is known about its organic-inorganic compositions. In organic SPM studies, Wei et al. (2004) pointed out that diatoms and dinoflagellates were the dominant phytoplankton groups in the Bohai Sea. The size fractional features of phytoplankton community in the Bohai Sea showed that nanophytoplankton was dominant, followed by picophytoplankton and microphytoplankton (Sun et al., 2002; Ning et al., 2002). In inorganic SPM studies, most of sediment grain size measurements were conducted with the seabed sediment or remote sensing analysis $\mathrm{Hu}$ et al., 2009; Qing et al., 2014; Wang et al., 2013), but in situ measurements of PSD in the water column were rare (Zeng et al., 2011). Therefore, previous studies provided general knowledge of PSD in the Bohai Sea, while most of them were indirect measurements and scarce effort has been made to resolve organic-inorganic compositions of SPM.

Specific aim of this study is to advance our knowledge on PSD and organic-inorganic SPM compositions in the Bohai Sea based on the data set measured concurrently by LISST and physical samples at 43 stations in summer 2014. For this purpose, the field survey and data collection methods are firstly introduced in Section 2. Further in Section 3, the specific features of the physical system are described based on the field measurements in the Bohai Sea. The PSD shapes from LISST are shown in Section 4. Then, the SPM compositions from physical samples and LISST are discussed in Section 5. The conclusions are given in Section 6.

\section{Data and Methods}

\subsection{Cruise and Sampling}

Data used in this study were collected at 43 stations in the Bohai Sea and North Yellow Sea from August 28 to September 8 in 2014 (Fig.1). Water samples were collected by a SeaBird CTD (SBE25 Plus) equipped with Niskin bottles at $10 \mathrm{~m}$ depth and in bottom layer, and temperature, salinity, pressure, chlorophyll and turbidity were recorded at the same time with sampling frequency $1 \mathrm{~Hz}$. Water samples in the surface layer were collected using a clean bucket. The PSD were measured using a LISST-100X Type-B particle size analyzer with sampling frequency $1 \mathrm{~Hz}$. A bottom-mounted quadrapod equipped with a RDI 600K ADCP (Acoustic Doppler current profiler) was deployed at several stations to measure the current speed with sampling frequency $0.33 \mathrm{~Hz}$.

\subsection{PSD Measurements from LISST}

LISST-100X Type-B instrument launches a laser beam and the beam will forward scattering by the SPM in the water which is detected by 32 annular ring detectors. 
Scattering information recorded by the ring detectors is mathematically inverted to get the size distribution which is presented as particle volume concentration, $\mathrm{V}(\mathrm{D})$, with units of micro-liters per liter $\left(\mu \mathrm{LL}^{-1}\right)$ in each of the 32 log-spaced size bins $(1.25-250 \mu \mathrm{m}$ in diameter for Type-B LISST). D represents the average diameter of each size bin. Previous studies showed that LISST produced false particle volume concentration peaks at both ends of the ring detectors (Davies et al., 2012; Mikkelsen and Pejrup, 2000; Traykovski et al., 1999). In consistency with this, our results also showed that abnormal particle volume concentrations were measured when the particle size is finer than $2 \mu \mathrm{m}$ and coarser than $119 \mu \mathrm{m}$. Therefore, only 25 particle size classes (particle diameter between 2-119 $\mu \mathrm{m})$ detected by LISST are used in this study.

\subsection{Organic-Inorganic Compositions of SPM Measured by Physical Samples}

Total suspended matter (TSM) mass of the water samples were obtained by filtration on Whatman $\mathrm{GF} / \mathrm{F}$ filters $(0.7 \mu \mathrm{m})$. The filters were re-combusted at $550^{\circ} \mathrm{C}$ for $2 \mathrm{~h}$, washed by pure water and preweighed before filtering. The water samples were divided into three groups based on their SPM concentration. The filtration volume of water samples collected from upper layer in shallow and deep stations (usually with low SPM concentration) were $2.5 \mathrm{~L}$ and $5 \mathrm{~L}$, respectively. In the bottom layer of the stations, water samples with volume of $1.5 \mathrm{~L}$ were filtered. The filters samples were rinsed by pure water and dried at $60^{\circ} \mathrm{C}$ for $24 \mathrm{~h}$. The filters were weighed to measure the TSM mass. To make sure the filters were dried completely, the filters were dried again at $60^{\circ} \mathrm{C}$ for $24 \mathrm{~h}$ and weighed until the filter weight fluctuation is less than 0.1 mg. The concentration of TSM was calculated based on the water sample volume and the weight difference before and after filtration.

The filters were fumigated by $36 \%-38 \%$ concentrated hydrochloric acid for $24 \mathrm{~h}$ and rinsed three times by pure water to remove the residual acid and digested dissolved matter. The Whatman GF/F filters are glass microfiber filters which are effectively resistant to acid erosion. Weighed the filters following the above-mentioned weighing procedure and the POM mass was determined by the weight difference before and after fumigation and PIM mass was obtained by subtracting POM mass from TSM mass. It should be noted that the standard method for partition of organic production in SPM is ignition method (Pearlman et al., 1995). A cruise in the western Bohai Sea was conducted in August 2015 (21 stations in this study were overlapped), and the POM/TSM measured by ignition method was conducted to verify the fumigation results in this study. The comparisons between ignition- and fumigation-derived POM/TSM results show that the POM/ TSM distribution patterns are similar in these two cruises (Fig.2), both of them having high POM ratio in the offshore area and low POM ratio in the nearshore area. But POM content derived from fumigation method was overestimated about $9 \%$ and $18 \%$ in the surface and bottom layers, respectively. The errors from fumigation method are acceptable, because there are also bias errors using ignition method caused by loss of structural water of clay minerals in the ashing step and filter material loss during combustion procedures (Röttgers et al., 2014; Stavn et al., 2009).

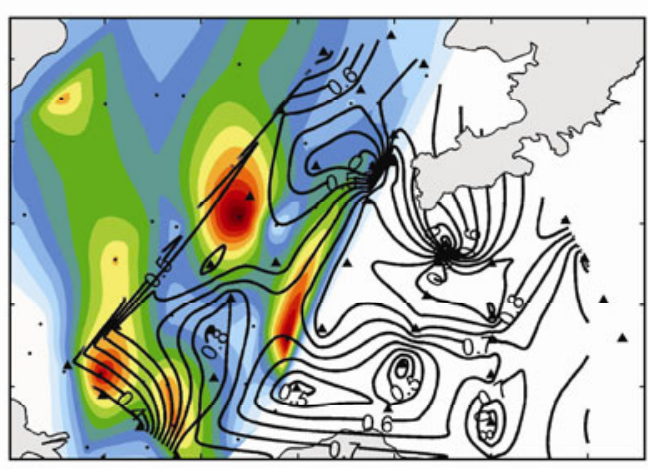

(a) Surface layer

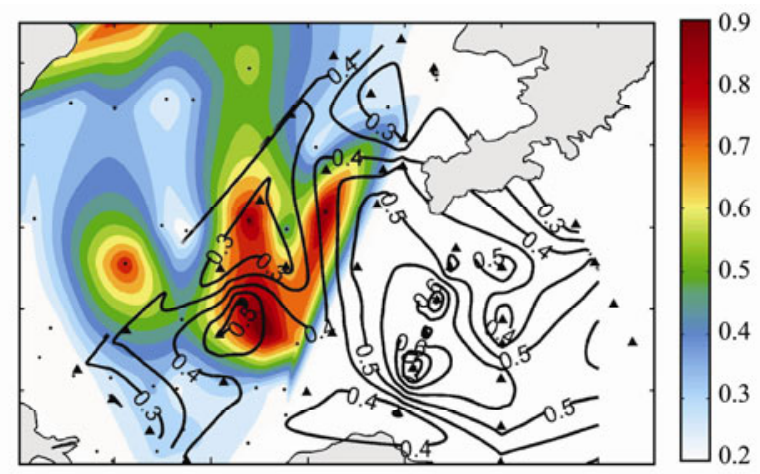

(b) Bottom layer

Fig.2 Horizontal distribution of (a) ratio of POM in the TSM (TSM=POM+PIM) in the surface layer of 2014 (filled color) and 2015 (black contour line), (b) ratio of POM in the TSM in the bottom layer 2014 (filled color) and 2015 (black contour line). Survey stations in 2014 and 2015 are marked using black triangles and points, respectively.

\section{Hydrographic Conditions}

The horizontal distribution of temperature, salinity, chlorophyll and turbidity in the surface layer, $10 \mathrm{~m}$ layer and bottom layer are shown in Fig.3. In the surface and $10 \mathrm{~m}$ layers, temperature was generally higher than $24^{\circ} \mathrm{C}$ with lower temperature (about $20^{\circ} \mathrm{C}$ ) in the northern and middle areas (Fig.3a). Owing to the cold intrusion water from the Yellow Sea, temperature in the bottom layer decreased dramatically from more than $21^{\circ} \mathrm{C}$ in the southern coastal sea to $6^{\circ} \mathrm{C}$ in the northern Bohai Strait. Similarly, salinity was also greatly affected by the salty water from the Yellow Sea, with the highest salinity of 31.7 in the northern Bohai Strait and the lowest $(<28.8)$ near the Yellow River estuary (Fig.3b). The distribution of salinity showed no obvious difference among the three layers. The chlorophyll concentration was higher in the 
surface and $10 \mathrm{~m}$ layers, ranging from 0.1 to $6.2 \mathrm{mg} \mathrm{m}^{-3}$. High chlorophyll concentrations $\left(>4.0 \mathrm{mg} \mathrm{m}^{-3}\right)$ were observed in the offshore area (Fig.3c). The chlorophyll concentrations in the bottom layer was relatively low with an average value of $0.7 \mathrm{mg} \mathrm{m}^{-3}$. The turbidity which reflects SPM concentration in the water column decreased seawards in all three layers, with the lowest and highest turbidity in the surface and bottom layers, ranging from 0.07 to $4.84 \mathrm{NTU}$ and 0.63 to $10.16 \mathrm{NTU}$, respectively (Fig.3d). (a)

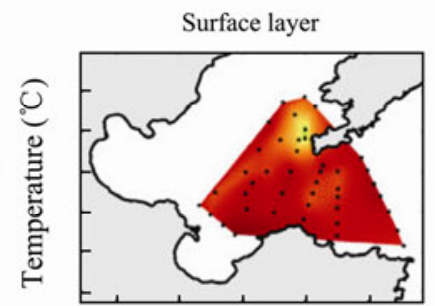

(b)

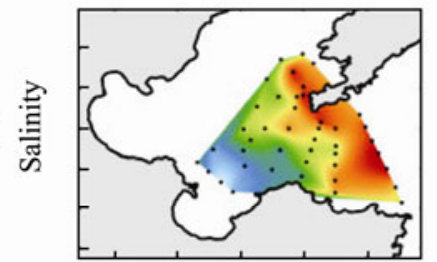

(c)

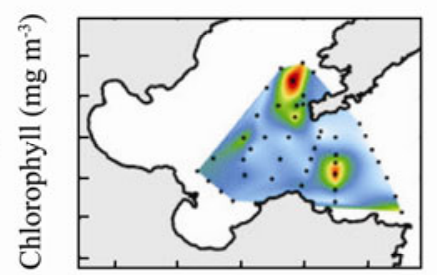

(d)

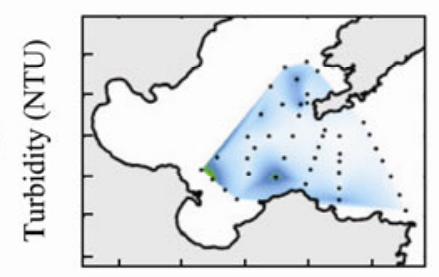

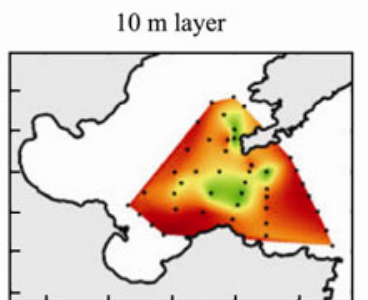
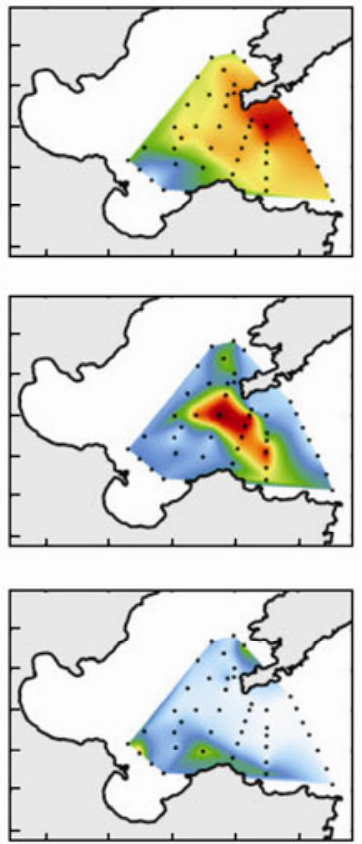
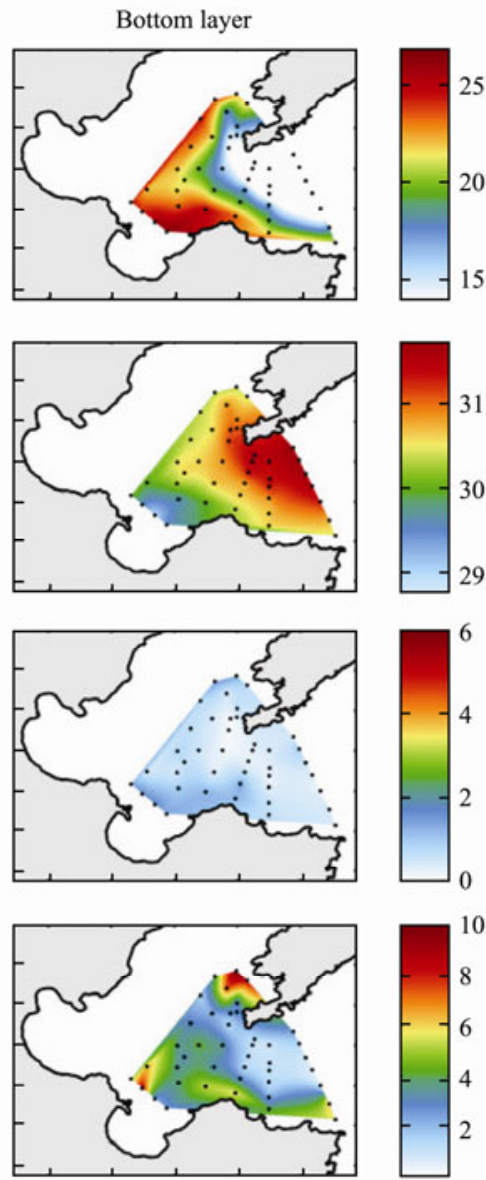

Fig.3 Horizontal distribution of (a) temperature $\left({ }^{\circ} \mathrm{C}\right)$, (b) salinity, (c) chlorophyll $\left(\mathrm{mg} \mathrm{m}^{-3}\right)$ and (d) turbidity (NTU) in the surface layer, $10 \mathrm{~m}$ layer and bottom layer of the Bohai Sea. Data were measured by CTD.

Strong thermocline and halocline were observed at the Bohai Strait and Laotieshan Channel, while the water column was well mixed in the coastal area with water depth less than $20 \mathrm{~m}$ (Fig.4). One exception was shown at the western stations of transect A: no obvious stratification was observed in the water column of its western stations even the water depths were deeper than $40 \mathrm{~m}$. This is because there was a strong wind event during the measurements, and the strong winds induced strong vertical mixing which broke the stratification at these stations. The vertical distribution of chlorophyll concentration was greatly affected by the thermocline. The highest chlorophyll concentration appeared around thermocline layer and the lowest chlorophyll concentration was measured beneath it. In transects with well-mixed water column, the chlorophyll concentration was slightly higher in the upper layer. The turbidity in the bottom layer was obviously higher than that in the surface layer in all transects. Especially in transects with strong stratifications, the thermocline hindered the turbid water transported from bottom to the sea surface.

\section{Particle Size Distribution Measured by LISST}

Frequency distributions of SPM grain size were used to group and organize the SPM with similar distribution shapes (Fig.5). Four typical PSD shapes were observed in the study area: right-peak, left-peak, double-peak and negative-skew shapes. The right-peak and left-peak PSD shapes indicated that the SPM contained predominantly coarse and fine particles, respectively. The double-peak shape indicated that the fine and coarse particles were well sorted, while the negative-skew shape meant that the SPM were badly sorted and the coarse particles were dominant. In the surface and $10 \mathrm{~m}$ depth layers, the right-peak shape dominated the Laotieshan Channel stations and the negative-skew shape was generally observed in the coastal area, while the double-peak shapes were observed at the stations along $121.5^{\circ} \mathrm{E}$ and the northwestern part of study 
field. The most significant feature of PSD in the bottom layer was that the negative-skew shape dominated in the coastal area, and the other three shapes were observed only in the Laotieshan Channel. The distribution of particle volume concentration was similar to that of turbidity in the survey area, showing high particle volume concentrations in the bottom layer $\left(0.04\right.$ and $\left.27.94 \mu \mathrm{LL}^{-1}\right)$ and the lower ones in the upper layer $\left(0.07\right.$ and $\left.9.25 \mu \mathrm{LL}^{-1}\right)$.

Marked intra-tidal variations of current speed were observed in the coastal area of the Bohai Sea, which leads to strong variations of bottom shear stress and vertical mixing. The bottom shear stress and vertical mixing were the main forces of sediment erosion and vertical sediment transport. As a result, the PSD shape may change due to variations of hydrological driving forces. For example, at
Station A (Fig.5a), Fig.6a shows variations of vertical profiles of particle volume concentration for different particle sizes, the measurements being conducted when the flood and ebb tide occurred; Fig.6b shows the corresponding current profiles when the measurements of particle volume concentration were conducted. At flood stages (20:30 and 02:00), the bottom layer PSD shape was negative-skew with particle volume concentration higher in the bottom layer and being decreased at ebb stages (23:00 and 05:00), especially for the medium size particles $(20$ $40 \mu \mathrm{m})$ with PSD double-peak shape. To better distinguish the change of the PSD shapes, particle volume concentrations in the surface $(3 \mathrm{~m})$ and bottom $(18 \mathrm{~m})$ layers were taken to show the PSD shapes at flood and ebb stages (Fig.6c). In the surface layer, the intra-tidal
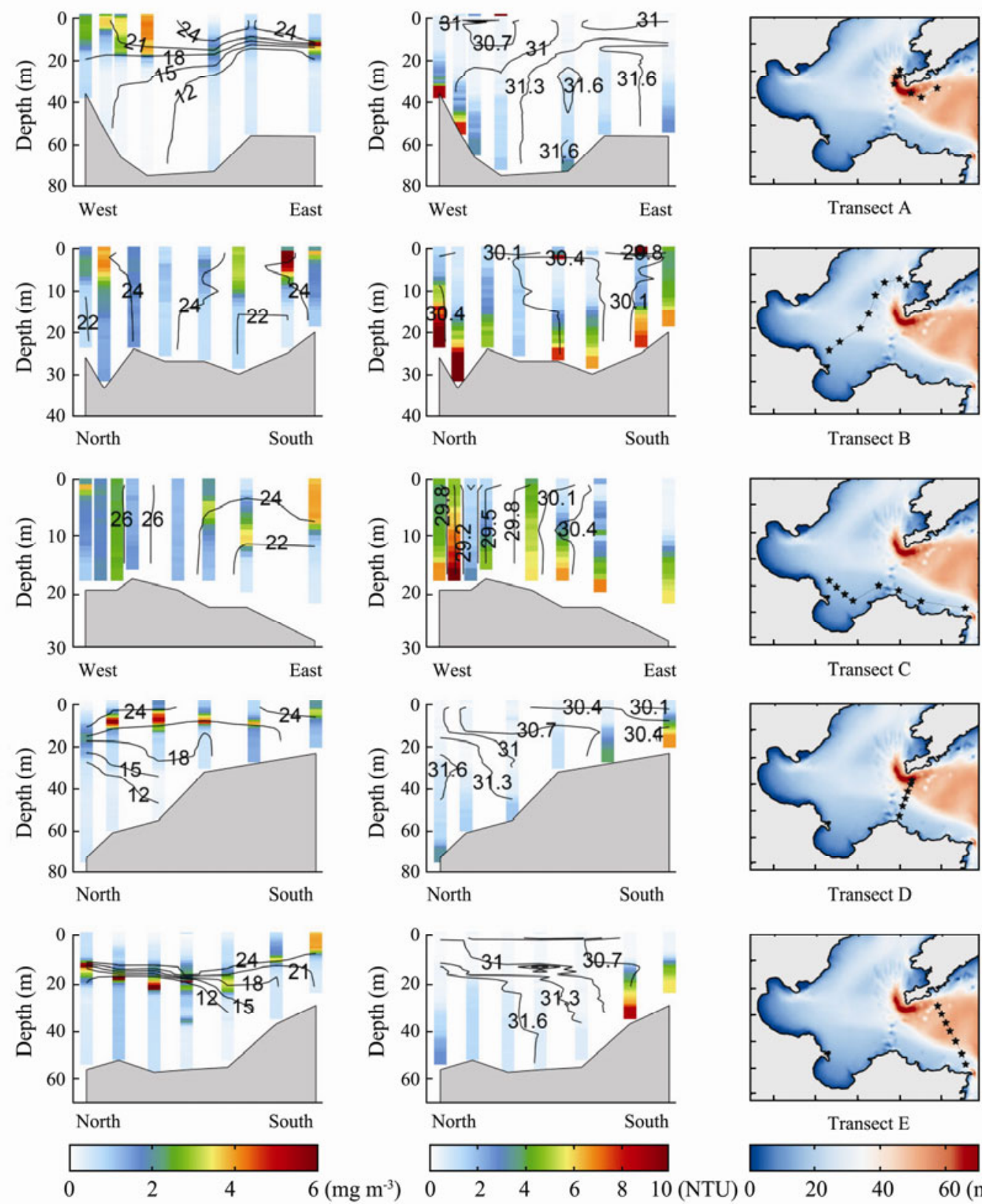

(a)

(b)

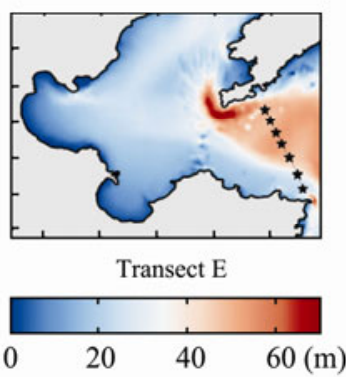

(c)

Fig.4 Vertical distribution of (a) temperature $\left({ }^{\circ} \mathrm{C}\right.$, contour line) and chlorophyll ( $\mathrm{mg} \mathrm{m}^{-3}$, color bar), (b) salinity (contour line) and turbidity (NTU, color bar), (c) transect locations. Data were measured by CTD. 

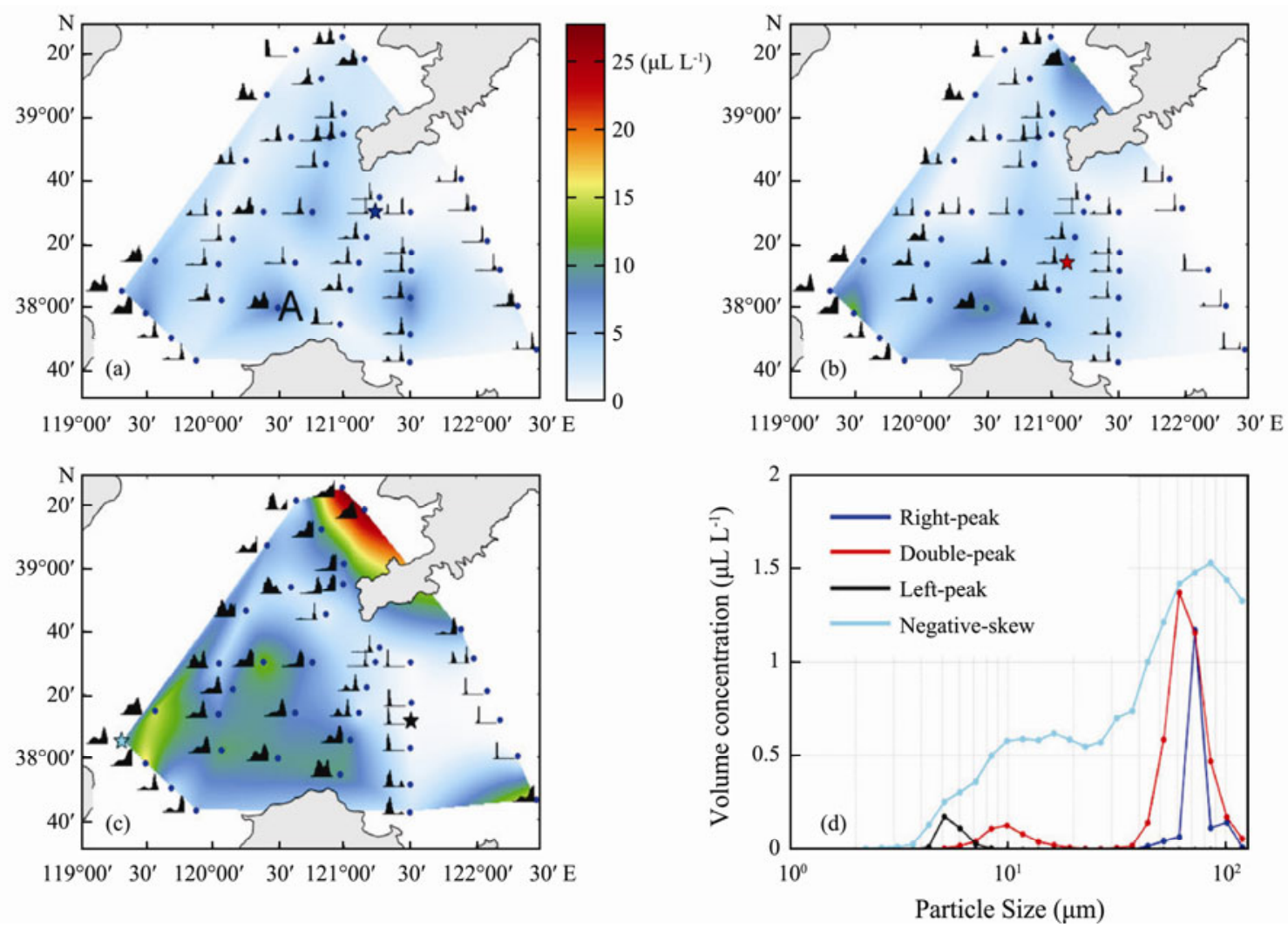

Fig.5 Frequency distribution of SPM grain size classes in corresponding stations (black charts) and particle volume concentration (filled color) in the (a) surface layer, (b) $10 \mathrm{~m}$ layer, (c) bottom layer and (d) PSD measured from four stations (color stars in Figs.5a-c) are taken as examples of four typical PSD shapes. Data were measured by LISST instrument.
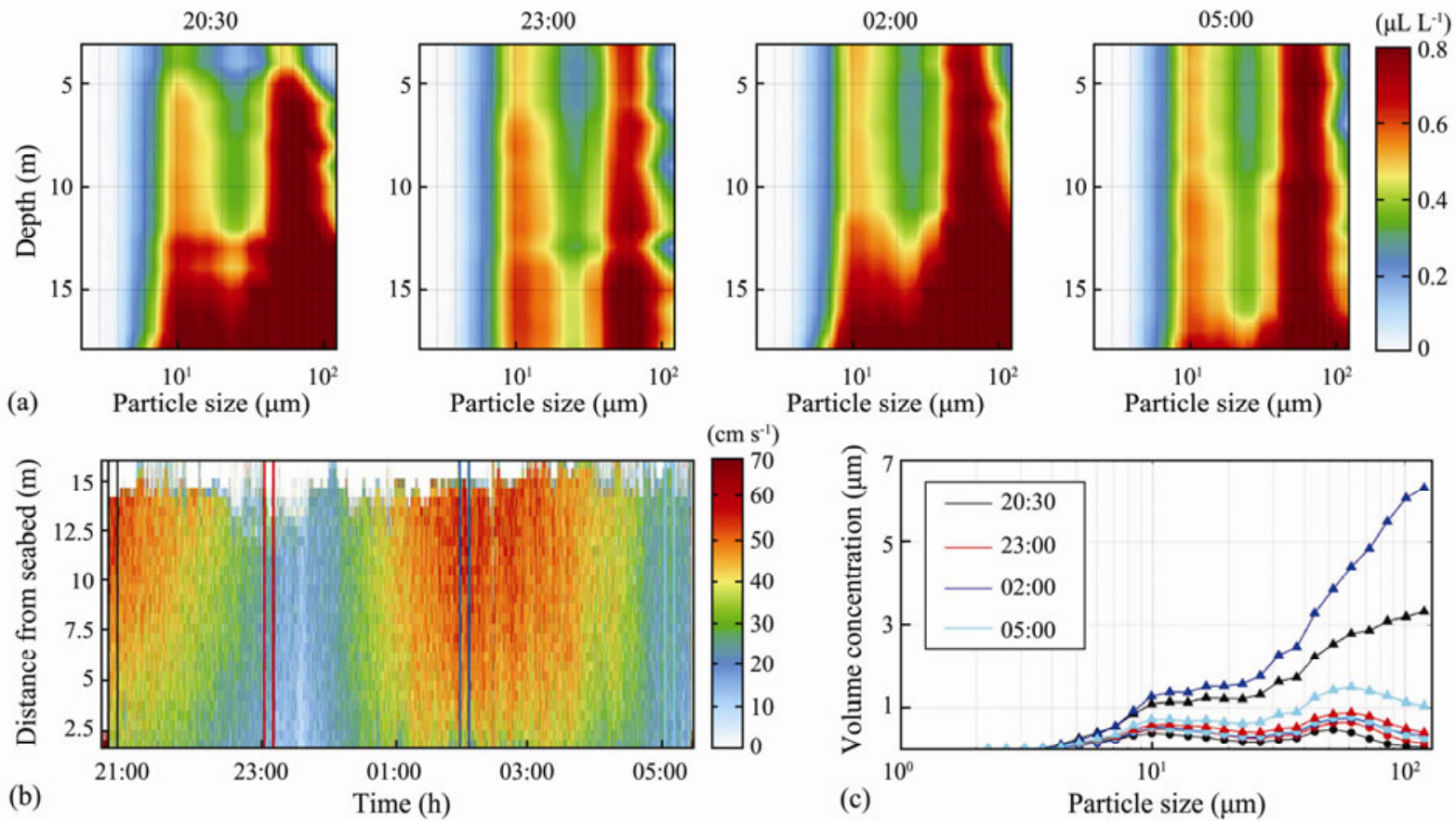

Fig.6 (a) Vertical profiles of particle volume concentration of station A at 20:30, 23:00, 02:00 and 05:00. Location of station A are shown in Fig.5a. (b) time series of current speed profiles at station A. (c) particle volume concentration at different times in the surface layer $(3 \mathrm{~m})$ and bottom layer $(18 \mathrm{~m})$ of station A. Different colors correspond to different times and particle volume concentrations in the surface and bottom layers marked by points and triangles, respectively.

variations of hydrology dynamics slightly affected the particle volume concentration, with double-peak shape occurring in flood and ebb stages. In the bottom layer, the hydrodynamics greatly influenced the PSD shapes. At ebb stages, the PSDs were similar to those in surface layer with low volume concentration and double-peak 
shape. However, at flood stages, a large amount of sediment was stirred and entered the water column and the particle volume concentration increased in the bottom layer. The volume concentration of coarse particles (diammeter $>40 \mu \mathrm{m}$ ) increased dramatically, resulting in the transfer of PSD shapes from the double-peak to negativeskew shape

\section{Organic-Inorganic Compositions of SPM}

\subsection{Organic-Inorganic Compositions of SPM Measured from Water Samples}

POM concentration was lowest in the surface layer with mean value of $1.93 \mathrm{mg} \mathrm{L}^{-1}$ for the entire survey regions, and it increased southwards with a range of 0.54 to 3.12 $\mathrm{mg} \mathrm{L}^{-1}$ (Fig.7a). The distribution of POM concentration in the $10 \mathrm{~m}$ layer was similar to that in the surface layer, but with a higher mean concentration of $2.45 \mathrm{mg} \mathrm{L}^{-1}$. The highest POM concentration appeared in the bottom layer with the mean value of $3.12 \mathrm{mg} \mathrm{L}^{-1}$ and it increased from offshore area to coastal area with a range of 0.82 to 6.91 $\mathrm{mg} \mathrm{L}^{-1}$. The distribution of PIM concentration was similar in all the three layers, with the highest PIM concentrations in the coastal area and the lowest in the Laotieshan Channel (Fig.7b). The PIM concentration increased downwards with mean concentration values of 1.32, 2.02 and $5.01 \mathrm{mg} \mathrm{L}^{-1}$ in the surface layer, $10 \mathrm{~m}$ layer and bottom layer, respectively. The POM proportion of SPM showed high fractions of organic matters in the surface and $10 \mathrm{~m}$ depth layers (on average $63 \%$ of particulates). In the bottom layer, the POM proportion decreased greatly and contributed only $42 \%$ of the particles. High POM proportions occurred in the Laotieshan Channel, with the highest values of $97 \%$ and $77 \%$ in the upper and bottom layers, respectively. In summer the Yellow River input might be a contributor to PIM. The low POM proportions were observed in the western part of transect H (Fig.8c) near the Yellow River estuary.

(a)
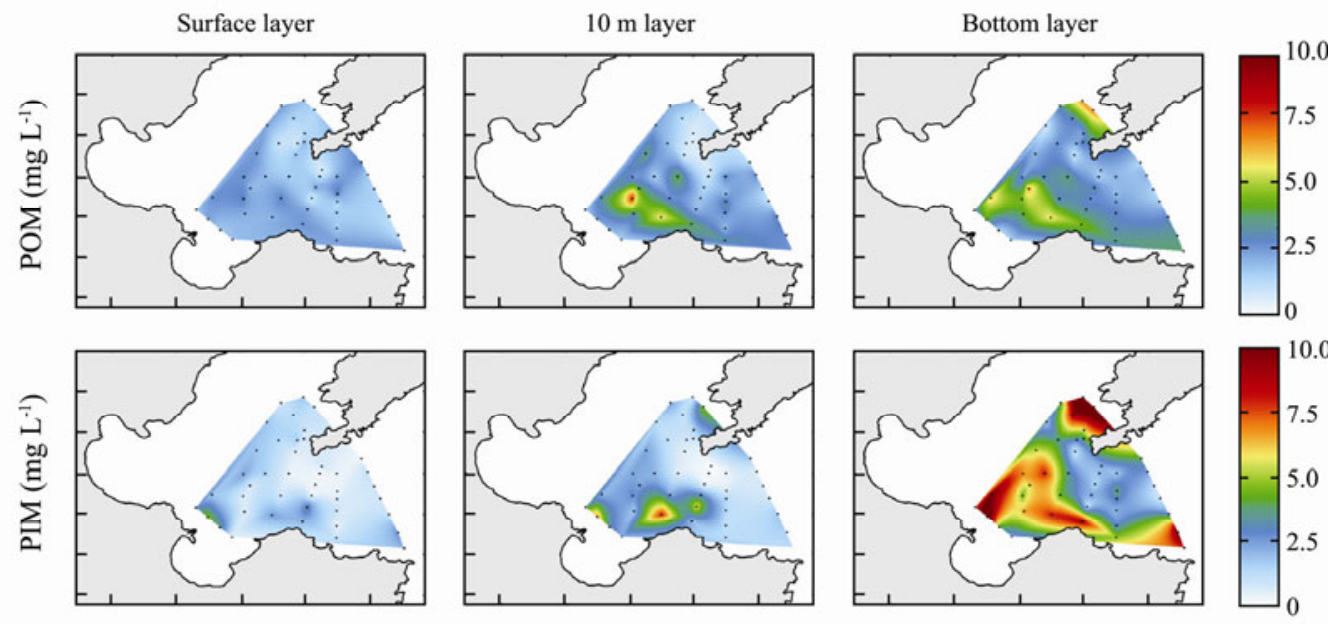

(c)
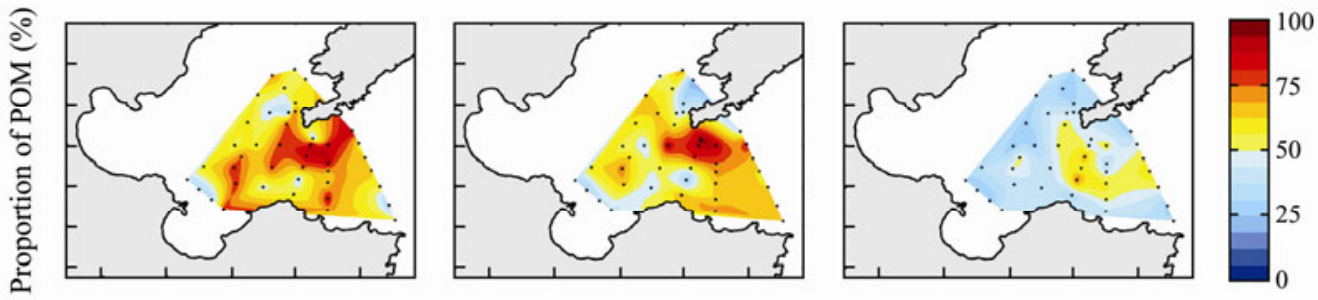

Fig.7 Distribution of (a) POM mass concentration $\left(\mathrm{mg} \mathrm{L}^{-1}\right)$, (b) PIM mass concentration $\left(\mathrm{mg} \mathrm{L}^{-1}\right)$ and (c) percentage of POM in the TSM in the surface layer, $10 \mathrm{~m}$ layer and bottom layer of the Bohai Sea. Data were measured from water samples.

\subsection{Dominant Size Range of Organic and Inorganic Matters}

Vertical profiles of particle volume concentration for different SPM sizes were used to identify the size of POM and PIM in three typical transects in the Bohai Sea (Fig.8). In Transect F, coarse particles $(40-100 \mu \mathrm{m})$ were observed in the upper layer of all six stations, while the corresponding coarse particles was not present in the bottom layer at most stations (Fig.8a). Usually, coarse inorganic particles cannot stay in the water column for a long time due to their high settling velocity, except under strong hydrodynamic conditions. Even if coarse inorganic particles were present in the water column, there should be more coarse particles in the bottom layer than in the upper layer. Therefore, the coarse particles of the upper layer in Transect F should be planktons. Similarly in Transect G, coarse particles contributed greatly to particles with sizes between 40 and $100 \mu \mathrm{m}$, indicating the dominance of planktonic organisms in coarse particles (Fig.8b). Moreover, in Transect G, coarse particles were also observed in the bottom layer with exactly the same size range as in the upper layer. These coarse particles in the bottom layer might consist of the sedimentation of 
plankton from the upper layer and the re-suspended dead plankton on the seabed. Actually, coarse particles with the size range of $40-100 \mu \mathrm{m}$ were observed in most survey stations and these coarse particles were present in the whole water columns at most stations. As for these coarse particles, only planktons were able to stay in the water column because their densities were very low and they were readily to be stirred into water column from the seabed. The hydrology environment in the study area was also unfavorable to flocculation processes. Therefore, it can be conclude that the principal composition of coarse particles with size range of $40-100 \mu \mathrm{m}$ was plankton.

In the upper layer of the study area, fine particles with grain size range of 4-20 $\mu \mathrm{m}$ were observed at most stations of these transects. The vertical variation patterns of particle volume concentration were similar between these fine particles and the aforementioned coarse size planktons in the upper layer (Fig.8), which suggests that the fine particles in the upper layer of Transect $F$ were related with plankton. Previous studies on phytoplankton size suggested that nanophytoplankton $(2-20 \mu \mathrm{m})$ was the major component of phytoplankton community and the microphytoplankton $(20-200 \mu \mathrm{m})$ was also important in the Bohai Sea (Sun et al., 2002; Ning et al., 2002). Therefore, these fine and coarse particles should be nanophytoplankton and microphytoplankton, with the size range of 4-20 $\mu \mathrm{m}$ and 40-100 $\mu \mathrm{m}$, respectively. Even though the volume concentrations of microphytoplankton were about 10 times higher than the volume concentration of nanophytoplankton, the nanophytoplankton abundance was much higher due to their small cell size. These results are consistent with previous studies (Sun et al., 2002; Ning et al., 2002). Therefore, it can be conclude that the principal composition of fine particles with size range of 4-20 $\mu \mathrm{m}$ was nanophytoplankton in the survey area. Similar to microphytoplankton, nanophytoplankton was present in the whole water column at most stations (Figs.5 and 8).

Medium-size particles $(20-40 \mu \mathrm{m})$ measured in the survey area were mainly from the resuspension of inorganic sediments on the seabed. Firstly, previous studies on surface sediment size showed that silt $(4-62.5 \mu \mathrm{m})$ and fine $(62.5-125 \mu \mathrm{m})$ sand dominated the surface sediment of the coastal area and the offshore area, respectively (Hu et al., 2009; Wang et al., 2014), implying that the coastal area provides plenty of medium-size particles to be suspended, while the offshore area does not constitute a source of medium-size particles. Our results showed that most of medium-size particles were observed in the coastal area but they were rarely found in the offshore area (Figs.5 and 8), being consistent with the seabed sediment size distribution shape. Secondly, the mediumsize particles were mainly present in the bottom layer due to the high settling velocity of inorganic sediments, while only a small amount of them were observed in the upper layer in the coastal area due to the vertical mixing induced by strong tidal currents (Fig.6).

The particle volume concentration results from LISST suggested that the size of organic particles mainly ranged from 4 to $20 \mu \mathrm{m}$ and 40 to $100 \mu \mathrm{m}$ in the Bohai Sea, while most SPM ranging from 20 to $40 \mu \mathrm{m}$ were composed of inorganic sediments. Even though phytoplankton was the major component of the fine and coarse size particles, there were also inorganic fine and coarse particles in the survey stations, especially in the bottom layer of the coastal area. (a)

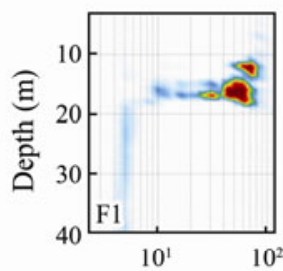

(b)

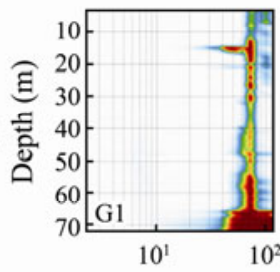

(c)

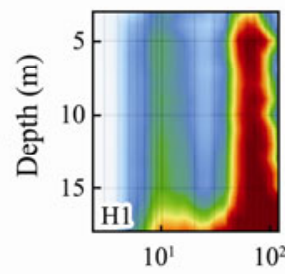

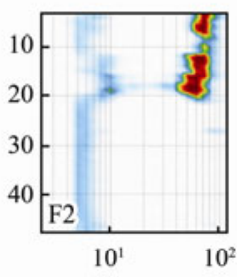
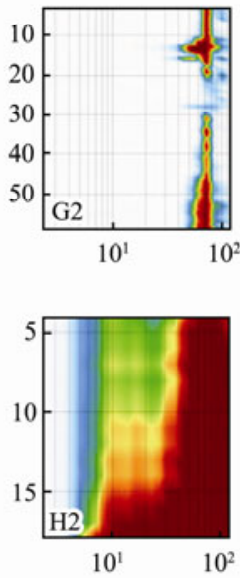
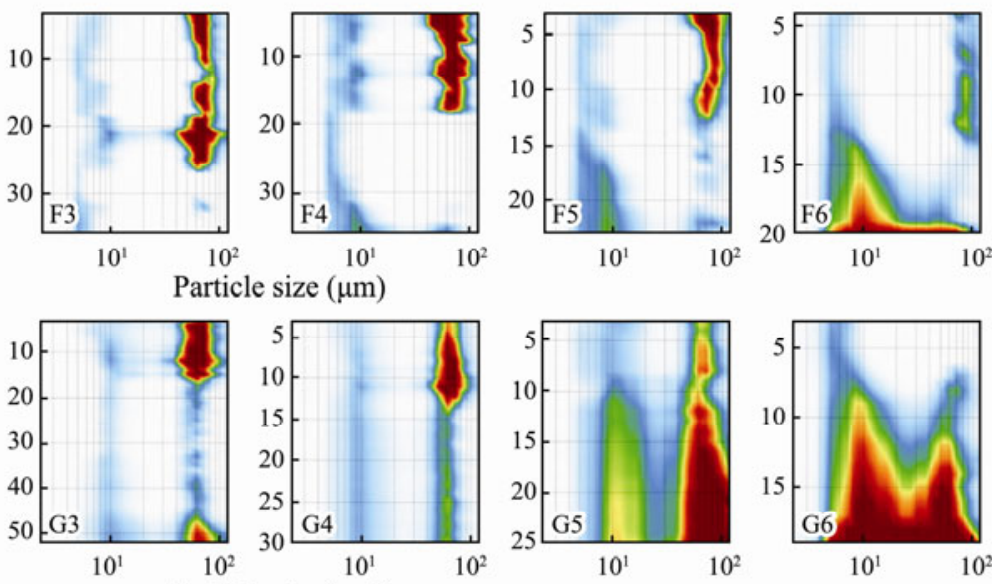

$\left(\mu \mathrm{L} \mathrm{L} \mathrm{L}^{-1}\right)$
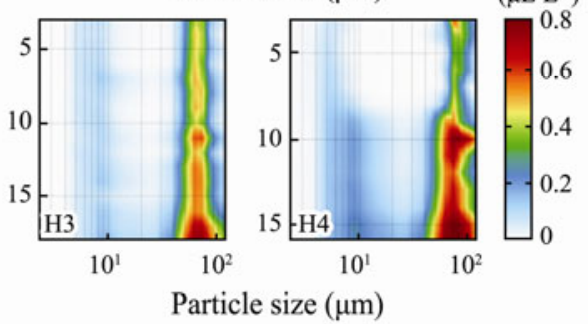

(d)

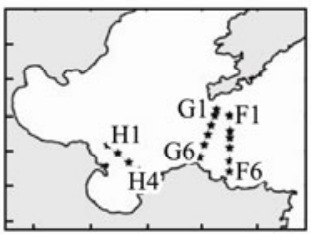

Fig.8 Vertical profiles of particle volume concentration for different particle sizes in (a) Transect F, (b) Transect G and (c) Transect H. Panel (d) shows the transect locations. 


\section{Conclusions}

Hydrology, PSD and SPM composition distributions of the Bohai Sea were studied based on field measurements in summer 2014. The field survey covered multiple hydrological environments (e.g., fresh and warm water mass in the Yellow River estuary, salty and cold water mass in the Laotieshan Channel and the mixed water mass from them), which in turn encompassed broad gradients in the SPM properties, such as PSD and SPM compositions. PSD results from LISST showed that there were four typical PSD shapes in the region, namely right-peak, leftpeak, double-peak and negative-skew shapes. The SPM composition results from water samples indicated that organic particles were in the majority in the upper layer of the Bohai Sea, while SPM were the mixture of organic and inorganic matters in the bottom layer.

Besides PSD information, LISST also provided reliable qualitative information of organic-inorganic compositions of SPM based on the particle size analysis. The results showed that particles with size ranges of 4-20 and 40$100 \mu \mathrm{m}$ mainly consisted of plankton while most of medium-size particles $(20-40 \mu \mathrm{m})$ consisted of inorganic sediment. These results were in a good agreement with those obtained from field samples and the hydrological results. Therefore, LISST is suitable for future studies on PSD and SPM compositions in the Bohai Sea, which can be easily used in the routine surveys and provides high time-spacial resolution result. However, no direct organic-inorganic particle size distribution measurements were conducted in the survey. The identification of organic-inorganic particle size of SPM in this study was based on the physical characters of the organic and inorganic particles and their regularities of distribution. The accuracy of using LISST to identify SPM composition should be verified in future study.

\section{Acknowledgements}

The field survey was supported by the Strategic Priority Research Program of the Chinese Academy of Sciences (No. XDA11020401). Survey data are available from Chair of the survey-Hua Zhang. The National Natural Science Fundation of China (Nos. 2015CB453300 and 41406013), the Natural Science Foundation Project of Shandong Province (No. ZR2010DZ002) and China Postdoctoral Science Foundation Grant (No. 2014M551956) also provided support for this work.

\section{References}

Alexander, C. R., DeMaster, D. J., and Nittrouer, C. A., 1991. Sediment accumulation in a modern epicontinental-shelf setting: The Yellow Sea. Marine Geology, 98 (1): 51-72.

Bornhold, B., Yang, Z., Keller, G., Prior, D., Wiseman, W., Wang, Q., Wright, L., Xu, W., and Zhuang, Z., 1986. Sedimentary framework of the modern Huanghe (Yellow River) delta. Geo-Marine Letters, 6 (2): 77-83.
Brewin, R. J. W., Sathyendranath, S., Lange, P. K., and Tilstone, G., 2014. Comparison of two methods to derive the sizestructure of natural populations of phytoplankton. Deep Sea Research Part I Oceanographic Research Papers, 85 (2): $72-$ 79.

Conan, P., Søndergaard, M., Kragh, T., Thingstad, F., Pvjo-Pay, M., Williams, P. J. le B., Markager, S., Cauwet, G., Borch, N. H., Evans, D., and Riemann, B., 2007. Partitioning of organic production in marine plankton communities: The effects of inorganic nutrient ratios and community composition on new dissolved organic matter. Limnology and Oceanography, 52 (2): 753-765.

Czuba, J. A., Straub, T. D., Curran, C. A., Landers, M. N., and Domanski, M. M., 2015. Comparison of fluvial suspendedsediment concentrations and particle-size distributions measured with in-stream laser diffraction and in physical samples. Water Resources Research, 51 (1): 320-340.

Davies, E. J., Nimmo-Smith, W. A. M., Agrawal, Y. C., and Souza, A. J., 2012. LISST-100 response to large particles. Marine Geology, 307-310 (5): 117-122.

de Moraes, P. C., Franco, D. C., Pellizari, V. H., and Gomes Sumida, P. Y., 2014. Effect of plankton-derived organic matter on the microbial community of coastal marine sediments. Journal of Experimental Marine Biology and Ecology, 461: 257-266.

Dong, J., Xia, X., Wang, M., Lai, Y., Zhao, P., Dong, H., Zhao, Y., and Wen, J., 2015. Effect of water-sediment regulation of the xiaolangdi reservoir on the concentrations, bioavailability, and fluxes of PAHs in the middle and lower reaches of the Yellow River. Journal of Hydrology, 527: 101-112.

Fettweis, M., Baeye, M., Van der Zande, D., Van den Eynde, D., and Joon Lee, B., 2014. Seasonality of floc strength in the southern North Sea. Journal of Geophysical Research: Oceans, 119 (3): 1911-1926.

Gao, X., Zhou, F., and Chen, C. A., 2014. Pollution status of the Bohai Sea: An overview of the environmental quality assessment related trace metals. Environment International, 62 (4): 12-30.

Gao, X., Zhuang, W., Chen, C. A., and Zhang, Y., 2015. Sediment quality of the SW coastal Laizhou Bay, Bohai Sea, China: A comprehensive assessment based on the analysis of heavy metals. PloS One, 10 (3): e0122190-e0122190.

Groundwater, H., Twardowski, M. S., Dierssen, H. M., Sciandra, A., and Freeman, S. A., 2012. Determining size distributions and composition of particles suspended in water: A new SEMEDS protocol with validation and comparison to other methods. Journal of Atmospheric and Oceanic Technology, 29 (3): 433-449.

Hu, L., Guo, Z., Feng, J., Yang, Z., and Fang, M., 2009. Distributions and sources of bulk organic matter and aliphatic hydrocarbons in surface sediments of the Bohai Sea, China. Marine Chemistry, 113 (3-4): 197-211.

Jiang, W., Pohlmann, T., Sun, J., and Starke, A., 2004. SPM transport in the Bohai Sea: Field experiments and numerical modelling. Journal of Marine Systems, 44 (3-4): 175-188.

Karageorgis, A. P., Georgopoulos, D., Kanellopoulos, T. D., Pagou, K., Kontoyiannis, H., Pavlidou, A., and Anagnostou, C., 2012. Spatial and seasonal variability of particulate matter optical and size properties in the Eastern Mediterranean Sea. Journal of Marine Systems, 105 (12): 123-134.

Li, Z., Li, L., Song, K., and Cassar, N., 2013. Estimation of phytoplankton size fractions based on spectral features of remote sensing ocean color data. Journal of Geophysical Research: Oceans, 118 (3): 1445-1458. 
Liu, C., Wang, J., Feng, J., and Peng, S., 2013. Effects of suspended particles on the growth of two dominant phytoplankton species of Bohai Bay, China. Marine Pollution Bulletin, 74 (1): 220-224.

Liu, F., Su, J., Moll, A., Krasemann, H., Chen, X., Pohlmann, T., and Wirtz, K., 2014. Assessment of the summer-autumn bloom in the Bohai Sea using satellite images to identify the roles of wind mixing and light conditions. Journal of Marine Systems, 129 (2): 303-317.

Markussen, T. N., and Andersen, T. J., 2013. A simple method for calculating in situ floc settling velocities based on effective density functions. Marine Geology, 344 (4): 10-18.

Meade, R., 1996. River-sediment inputs to major deltas. In: Coastal Systems and Continental Margins. Milliman, J., and Haq, B., eds., Springer Netherlands, 63-85.

Mikkelsen, O. A., and Pejrup, M., 2000. In situ particle size spectra and density of particle aggregates in a dredging plume. Marine Geology, 170 (3-4): 443-459.

Milliman, J. D., and Meade, R. H., 1983. World-wide delivery of river sediment to the oceans. The Journal of Geology, 91 (1): $1-21$.

Nair, A., Sathyendranath, S., Platt, T., Morales, J., Stuart, V., Forget, M., Devred, E., and Bouman, H., 2008. Remote sensing of phytoplankton functional types. Remote Sensing of Environment, 112 (8): 3366-3375.

Ning, X., Liu, Z., Cai, Y., and Liu, C., 2002. Size-fractionated phytoplankton standing stock and primary production in Bohai Sea during later spring. Studia Marina Sinica, 44: 22-33.

Pearlman, S. R., Costa, H. S., Jung, R. A., McKeown, J. J., and Pearson, H. E., 1995. Solids (Section 2540). In: Standard Methods for the Examination of Water and Wastewater. Eaton, A. D., et al., eds., American Public Health Association, Washington, 2: 53-64.

Pelling, H. E., Uehara, K., and Green, J. A. M., 2013. The impact of rapid coastline changes and sea level rise on the tides in the Bohai Sea, China. Journal of Geophysical Research: Oceans, 118 (7): 3462-3472.

Qiao, S., Shi, X., Zhu, A., Liu, Y., Bi, N., Fang, X., and Yang, G., 2010. Distribution and transport of suspended sediments off the Yellow River (Huanghe) mouth and the nearby Bohai Sea. Estuarine, Coastal and Shelf Science, 86 (3): 337-344.

Qing, S., Zhang, J., Cui, T., and Bao, Y., 2014. Remote sensing retrieval of inorganic suspended particle size in the Bohai Sea. Continental Shelf Research, 73: 64-71.

Renosh, P. R., Schmitt, F. G., Loisel, H., Sentchev, A., and Mériaux, X., 2014. High frequency variability of particle size distribution and its dependency on turbulence over the sea bottom during re-suspension processes. Continental Shelf Research, 77 (1): 51-60.

Reynolds, R. A., Stramski, D., Wright, V. M., and Woźniak, S. B., 2010. Measurements and characterization of particle size distributions in coastal waters. Journal of Geophysical Research: Oceans, 115 (C8): C08024.

Röttgers, R., Heymann, K., and Krasemann, H., 2014. Suspended matter concentrations in coastal waters: Methodological im- provements to quantify individual measurement uncertainty. Estuarine, Coastal and Shelf Science, 151: 148-155.

Stavn, R. H., Rick, H. J., and Falster, A. V., 2009. Correcting the errors from variable sea salt retention and water of hydration in loss on ignition analysis: Implications for studies of estuarine and coastal waters. Estuarine, Coastal and Shelf Science, $\mathbf{8 1}$ (4): 575-582.

Sun, J., Liu, D., Cai, X., and Zhang, C., 2003. The chlorophyll $a$ concentration and estimating of primary productivity in the Bohai Sea in 1998-1999. Acta Ecologica Sinica, 23 (3): 517526.

Sun, J., Liu, D., Yang, S., Guo, J., and Qian, S., 2002. The preliminary study on phytoplankton community structure in the central Bohai Sea and the Bohai Strait and its adjacent area. Oceanolgia et Limnologia Sinica, 33 (5): 461-471.

Sun, P., Li, R., Li, Y., Zhu, M., and Xu, Z., 2008. The netphytoplankton community structure of the Bohai Sea in late summer, 2005. Advances in Marine Science, 26 (3): 354-363.

Traykovski, P., Latter, R. J., and Irish, J. D., 1999. A laboratory evaluation of the laser in situ scattering and transmissometery instrument using natural sediments. Marine Geology, 159 (14): 355-367.

Wang, D., 2015. Remote sensing-based study on the temporal variations in chlorophyll- $a$ concentration after Confo oil spill in Bohai Sea. Journal of the Indian Society of Remote Sensing, 43 (1): 133-142.

Wang, H., Wang, A., Bi, N., Zeng, X., and Xiao, H., 2014. Seasonal distribution of suspended sediment in the Bohai Sea, China. Continental Shelf Research, 90: 17-32.

Wang, W., Fu, Y., Li, S., and Li, P., 2013. Distribution on surface sediment and sedimentary divisions in the middle part of Bohai Sea. Acta Sedimentologica Sinica, 31 (3): 478-485.

Wei, H., Sun, J., Moll, A., and Zhao, L., 2004. Phytoplankton dynamics in the Bohai Sea-Observations and modelling. Journal of Marine Systems, 44 (3-4): 233-251.

Xi, H., Larouche, P., Michel, C., and Tang, S., 2015. Beam attenuation, scattering and backscattering of marine particles in relation to particle size distribution and composition in Hudson Bay (Canada). Journal of Geophysical Research: Oceans, 120: $1-15$.

Yang, Z., and Liu, J., 2007. A unique Yellow River-derived distal subaqueous delta in the Yellow Sea. Marine Geology, 240 (1-4): 169-176.

Yang, Z., Ji, Y., Bi, N., Lei, K., and Wang, H., 2011. Sediment transport off the Huanghe (Yellow River) delta and in the adjacent Bohai Sea in winter and seasonal comparison. Estuarine, Coastal and Shelf Science, 93 (3): 173-181.

Yu, Y., Wang, H., Shi, X., Ran, X., Cui, T., Qiao, S., and Liu, Y., 2013. New discharge regime of the Huanghe (Yellow River): Causes and implications. Continental Shelf Research, 69 (6): 62-72.

Zeng, M., Fan, D., Sun, X., Wang, S., and Yang, Z., 2011. The grain-size distribution of the suspended particulate matter in the Huanghe Estuary and its adjacent sea area in winter. Acta Oceanologica Sinica, 30 (2): 75-83.

(Edited by Xie Jun) 